\title{
ЦЕЛЕВОЙ ГХ/МС АНАЛИЗ НЕФТЯНЫХ МАРКЕРОВ И ПРОДУКТОВ ИХ ДЕГРАДАЦИИ
}

\author{
Ю.С. Токсарова \\ Горный институт УрО РАН, г. Пермь
}

\begin{abstract}
Аннотация: Предложены схемы систематического анализа гомологических рядов нефтяных маркеров и их кислородсодержащих производных, базирующиеся на определении закономерности времени удерживания (RT) и аналитических серий фрагментарных и перегруппировочных ионов. Определены аналитические серии для карбоновых кислот и их эфиров. Показана значимость целевого анализа при расчетах геохимических индексов.

Ключевые слова: газовая хроматография/масс-спектрометрия, алифатические углеводороды, карбоновые кислоты, гомологический ряд, аналитическая серия.
\end{abstract}

Анализ сложных многокомпонентных смесей является традиционной проблемой как аналитической химии, так и геохимии. Одним из методов, позволяющих решить эту проблему, является хромато-масс-спектрометрия (ХМC). Тем не менее, при нецелевом анализе различных природных образцов, когда количество индивидуальных веществ измеряется сотнями, неизбежно возникают проблемы хроматографического разделения и идентификации веществ путем сравнения массспектров с библиотечными данными. Проблема идентификации может быть связана как с одновременным элюированием нескольких веществ, так и с отсутствием масс-спектров обнаруженных соединений в базах данных. Традиционный целевой анализ методом ХМС связан с использованием стандартов и в случае необходимости идентификации большого круга соединений приводит к существенным временным и финансовым затратам. Таким образом, наиболее рациональным подходом к работе со сложными матрицами является объединение методов нецелевого и целевого анализа.

Нами была опробована комбинация двух методов анализа (целевого и нецелевого) в ходе поиска нефтяных маркеров и продуктов их деградации в хлороформенном битумоиде (ХБА) образцов карналлита.

На первом этапе хлороформенный экстракт, растворенный в гексане, вводился в инжектор хроматографа и хроматограмма записывалась по полному ионному току (Total ion current, TIC), а идентификация производилась путем сличения с базой массспектров NIST. По результатам первого этапа для целевого анализа выбирались гомологические ряды, члены которых были обнаружены. Наиболее представительными оказались гомологические ряды н-алканов, алифатических кислот нормального строения и их эфиров.

На втором этапе анализировались масс-спектры гомологических рядов и определялись аналитические серии фрагментарных и перегруппировочных ионов. В серию брались ионы, которые характерны для всех членов ряда, включают в себя функциональные группы, определяющие принадлежность к данному ряду и имеющие максимально возможную интенсивность (для базового иона не менее 50\%).

Для разветвленных алканов и алканов нормального строения характерна «алкановая» серия ионов с $\mathrm{m} / \mathrm{z} 29,43,57,71,85 \ldots$ [1]. Поэтому в качестве базового иона для гомологический ряда н-алканов был выбран трет-бутильный ион с m/z 57. Пик этого иона имеет максимальную интенсивность за счет своей устойчивой разветвленной структуры, он присутствует в масс-спектрах н-алканов как перегруппировочный ион [2]. В качестве подтверждающих взяты ионы «алкановой» серии с $\mathrm{m} / \mathrm{z} 43$ и 71. 


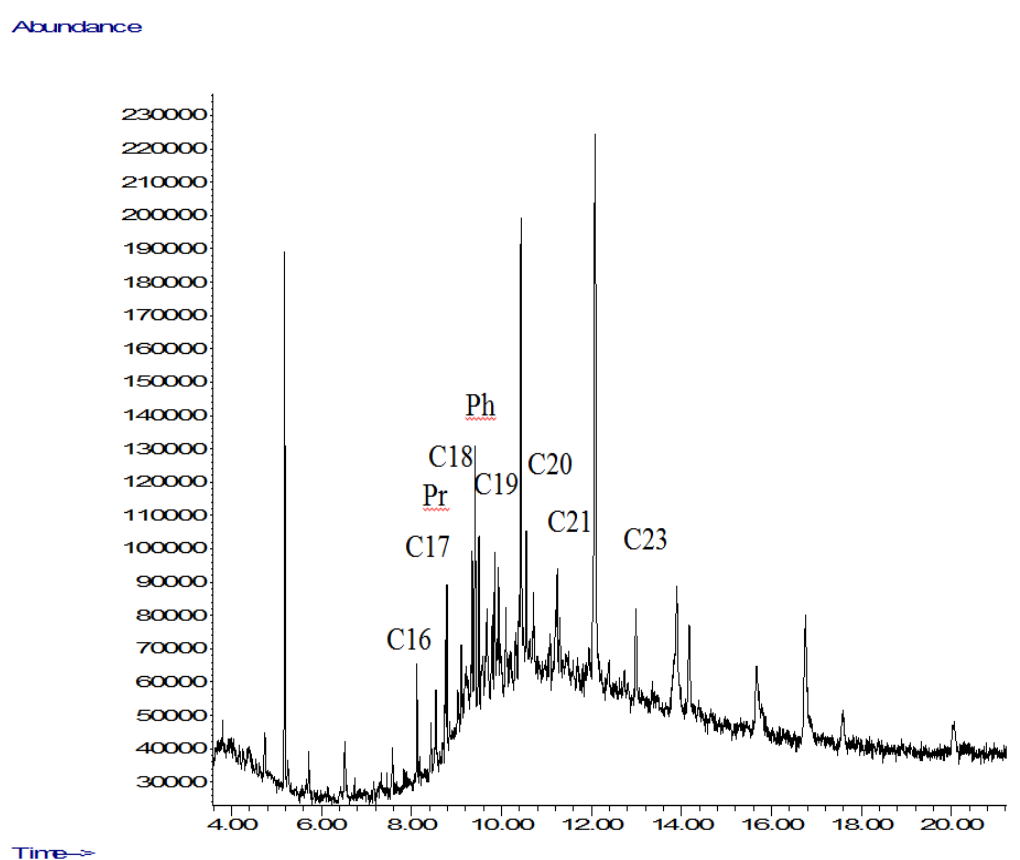

Рис. 1. Хроматограмма ХБА, записанная по полному ионному току

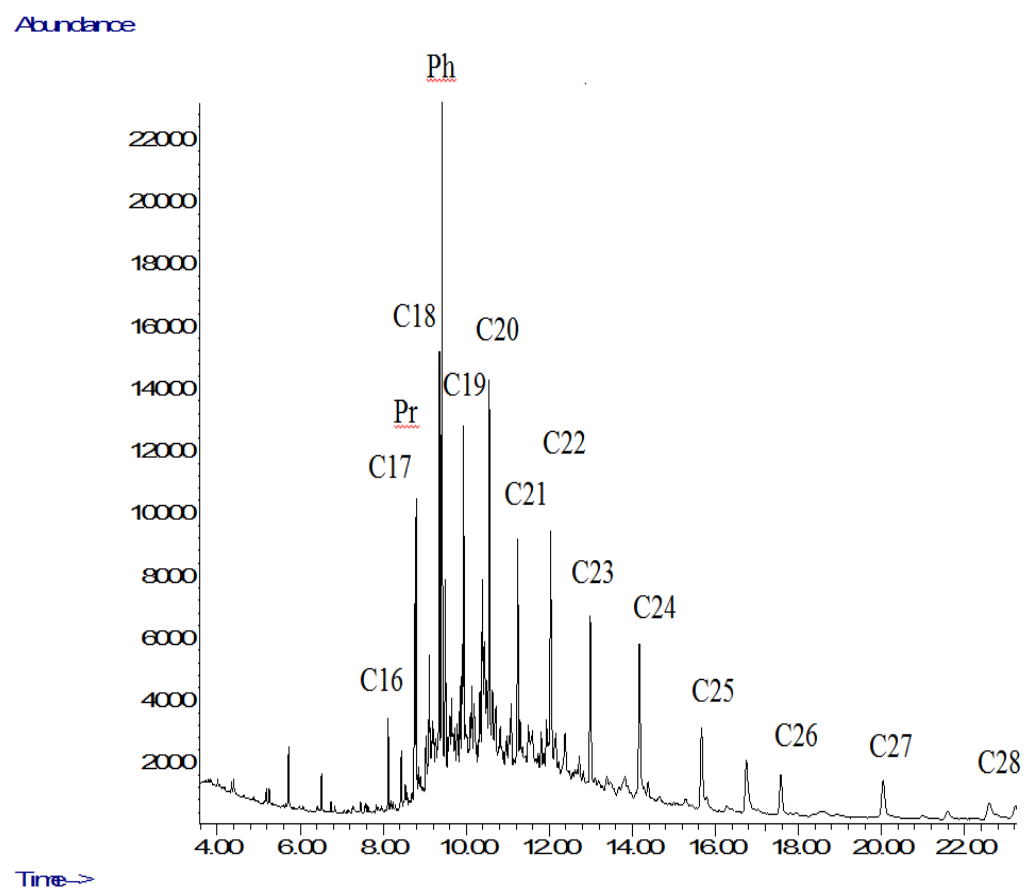

Рис.2. Хроматограмма ХБА, записанная в режиме сканирования по селективным ионам

В ходе нецелевого анализа были идентифицированы н-алканы $\left(\mathrm{C}_{16}-\mathrm{C}_{21}, \mathrm{C}_{23}\right)$, пристан $(\mathrm{Pr})$ и фитан $(\mathrm{Ph})$ (рис. 1). Целевой анализ, направленный на определение разветвленных алканов и алканов нормального строения, позволил обнаружить дополнительно налканы $\mathrm{C}_{22}, \mathrm{C}_{24}-\mathrm{C}_{28}$ (рис. 2), которые при записи масс-спектра по полному ионному току, маскировались ароматическими структурами.

Так, например, пик с значением RT 12.086 (пик максимальной интенсивности на рис. 1), характерный для докозана, имеет масс-спектр схожий со спектром алкил- $\alpha$-нафтола, что по-видимому связано с одновременным элюированием н-алкана $\mathrm{C}_{20}$ и ароматического бициклического углеводорода. Аналогичным образом маскируется присутствие минорных длинноцепочечных н-алканов $\mathrm{C}_{24}-\mathrm{C}_{28}$. Это связано с тем, что масс-спектры ароматических 
углеводородов содержат несколько очень интенсивных характеристических пиков ароматических ядер, стабилизированных системами сопряжения $\pi$-электронов, в то время как каждый пик «алкановой» сериии имеет сравнительно небольшую интенсивность.

Таким образом, целевой анализ позволил повысить чувствительность массселективного детектора к алифатическим структурам и устранить мешающее влияние сложной матрицы (рис. 1 и 2).

Расчет геохимических коэффициентов, полученных при разных режимах сканирования, наглядно демонстрирует, насколько велико влияние сложной природной матрицы. Наиболее зависимым от матрицы является отношение короткоцепочечных н-алканов к длинноцепочечным. Коэффициенты, отражающие соотношения пристана, фитана, гептадекана и октадекана, оказались более независимыми (таблица 1).

Таблица 1

Зависимость значений геохимических индексов от режима сканирования

\begin{tabular}{|l|c|c|}
\hline Геохимические коэффициенты & $\begin{array}{c}\text { По полному } \\
\text { ионному току }\end{array}$ & $\begin{array}{c}\text { По ионам } \\
\mathrm{c} \mathrm{m} / \mathrm{z} 43,57,71\end{array}$ \\
\hline Ряд н-алканов & $\mathrm{C}_{16}-\mathrm{C}_{23}$ & $\mathrm{C}_{16}-\mathrm{C}_{28}$ \\
\hline Максимум & $\mathrm{C}_{20}$ & $\mathrm{C}_{20}$ \\
\hline$\Sigma \mathrm{C} \leq 20 / \Sigma \mathrm{C} \geq 21$ & 2,85 & 0,80 \\
\hline НЧ/Ч & 1,06 & 0,74 \\
\hline Пристан/Фитан & 0,51 & 0,32 \\
\hline Пристан/n- $\mathrm{C}_{17}$ & 1,64 & 1 \\
\hline Фитан $/ \mathrm{n}-\mathrm{C}_{18}$ & 1,95 & 1,15 \\
\hline Пристан + Фитан $/ \mathrm{n}-\mathrm{C}_{17}+\mathrm{n}-\mathrm{C}_{18}$ & 1,83 & 1,36 \\
\hline
\end{tabular}

По аналогии с анализом алканов в сложных матрицах можно проводить целевой анализ других гомологических рядов, имеющих в масс-спектрах аналитическую серию фрагментарных ионов, например, ряды карбоновых кислот, их метиловых и этиловых эфиров и др. Для этого необходимо решить две задачи: а) определить оптимальное количество реперных гомологов, по которым будут интерполяцией определяться времена удерживания всех членов ряда; б) определить аналитическую серию, обеспечивающую селективность анализа. Ответ на первую задачу зависит в первую очередь от экономической целесообразности, ответ на вторую - это анализ направлений фрагментации молекулярного иона $\mathrm{M}^{+}{ }^{*}$ в заданных условиях масс-спектрометрии.

Так, для алифатических кислот $\left(\mathrm{R}^{1}=\mathrm{H} ; \mathrm{R}^{2}=\mathrm{Alk}\right)$, начиная с масляной, основным процессом фрагментации, приводящей к интенсивному пику в спектре, является перегруппировка Мак-Лаферти:

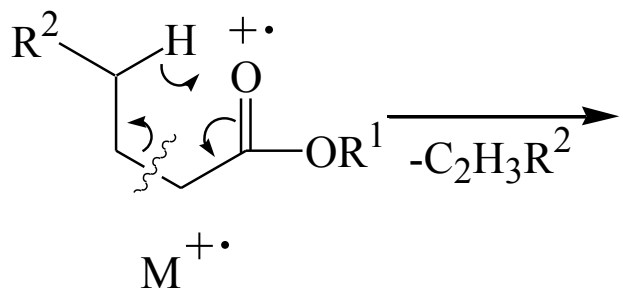<smiles></smiles>

A

В случае кислот нормального строения, а также разветвленных кислот, не имеющих заместителей, в $\alpha$-положении перегруппировка приводит к образованию иона с $\mathrm{m} / \mathrm{z} 60$ (A) [2]. 
По близкому механизму, но включающему миграцию атомов водорода из более дальних положений через интермедиаты $\left[\mathrm{I}^{1}\right]$ и $\left[\mathrm{I}^{2}\right]$, образуются ионы с m/z 73 (B) и m/z 129 (C):

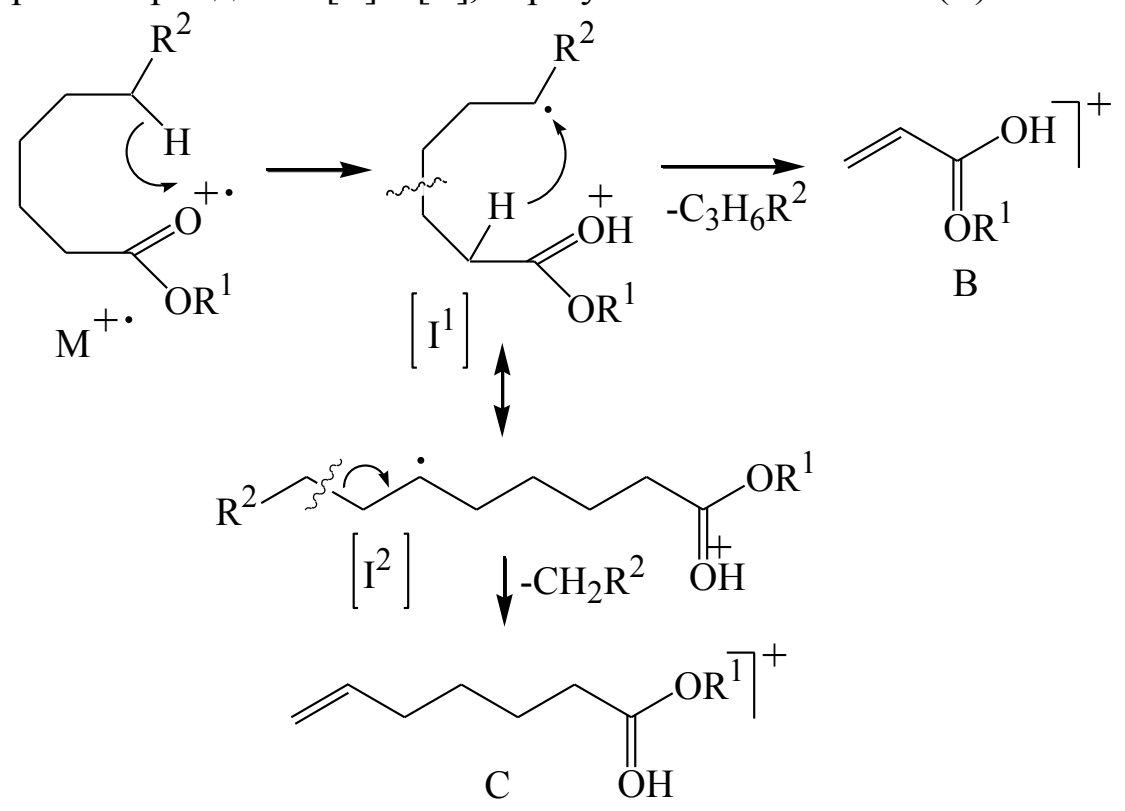

Таким образом, для всех предельных алифатических кислот характерно наличие интенсивных пиков с m/z 60, 73 и 129. Максимальная интенсивность у пика с m/z 73 .

Для метиловых $\left(\mathrm{R}^{1}=\mathrm{CH}_{3} ; \mathrm{R}^{2}=\mathrm{Alk}\right)$ и этиловых $\left(\mathrm{R}^{1}=\mathrm{C}_{2} \mathrm{H}_{5} ; \mathrm{R}^{2}=\mathrm{Alk}\right)$ эфиров н-карбоновых кислот аналитическая серия образована аналогичным набором перегруппировочных ионов $\mathrm{A}$, $\mathrm{B}, \mathrm{C} \mathrm{c} \mathrm{m/z} \mathrm{74,} \mathrm{87,} 143$ и 88, 101, 157, соответственно. Но, в отличие от аналитической серии свободных кислот, наибольшую интенсивность имеют ионы А. Поэтому базовыми ионами для сканирования будут ионы c m/z 74 для метиловых эфиров и с m/z 88 для этиловых.

Подводя итог выше изложенному, можно сделать вывод, что приемы нецелевого и целевого анализа в совокупности с накопленными данными масс-спектрометрии можно успешно применять при решении прикладных задач геохимии.

С этой целью предлагается следующая методика анализа.

Пробоподготовка осуществлялась методом жидкой экстракции в хлороформ с последующим растворением экстракта в гексане $[4,5]$. Условия анализа: хромато-масс-спектрометрическая система 6890N/5973N фирмы «AgilentTechnologies», хроматографическая колонка HP-5MS (5\%фенил-95\%-диметилполисилоксан) длиной 30 м, внугренним диаметром 0,25 мМ, с толщиной неподвижной фазы 0,25 мкм. Скорость газа-носителя (гелий) 1 мл/мин, давление 57,3 кПа. Программируемый нагрев от $80^{\circ} \mathrm{C}$ до $250^{\circ} \mathrm{C}$ со скоростью 70 град/мин, далее изотермический на верхней границе интервала. Температура интерфейса $250^{\circ} \mathrm{C}$, температура квадруполя $150^{\circ} \mathrm{C}$, температура источника ионов $230^{\circ} \mathrm{C}$. Задержка на растворитель 5 минуг, деление потока 1:10. Масс-спектр записывался по полному ионному току и в режиме сканирования селективных ионов.

Работа выполнена при поддержке Программы ФНИ, проект № 0422-2019-0149-С-01.

\section{БИБЛИОГРАФИЧЕСКИЙ СПИСОК}

1. Лебедев А.Т. Масс-спектрометрия в органической химии. - М.: БИНОМ. Лаборатория знаний. $-2003 .-493$ с.

2. Вульфсон Н.С., Заикин В.Г., Микая А.И. Масс-спектрометрия органических соединений. - М.: Хими, 1986. - 312 с.

3. Полякова А.А. Молекулярный масс-спектральный анализ нефтей. - М.: Недра, 1973. - 184 с.

4. Одинцова Т.А. Геохимическая характеристика состава аквабитумоидов нафтидного типа // Стратегия и процессы освоения георесурсов: сб. науч. тр. вып. 12 / ГИ УрО РАН. - Пермь, 2014. - С. 58-61.

5. Бачурин Б.А., Одинцова Т.А. Экоаналитическая идентификация источников органического загрязнения природных геосистем // Стратегия и процессы освоения георесурсов: сб. науч. тр. вып. 15 / ГИ УрО РАН. - Пермь, 2017. - С. 62-65. 